\title{
A Brief Analysis on Characteristics of the Inheritance of Traditional Jade Carving Art
}

\author{
Chenglin Ming, Wenjing Min \\ Hubei Province Institute of Arts and Crafts, Wuhan, China \\ Email:373701086@qq.com
}

How to cite this paper: Ming, C. L., \& Min, W. J. (2021). A Brief Analysis on Characteristics of the Inheritance of Traditional Jade Carving Art. Art and Design Review, 9, 341348.

https://doi.org/10.4236/adr.2021.94030

Received: October 26, 2021

Accepted: November 26, 2021

Published: November 29, 2021

Copyright (c) 2021 by author(s) and Scientific Research Publishing Inc. This work is licensed under the Creative Commons Attribution International License (CC BY 4.0).

http://creativecommons.org/licenses/by/4.0/ (c) (i) Open Access

\begin{abstract}
The development and inheritance of jade carving skills are the foundation of jade culture rooted in China. At present, the jade carving industry has entered a brand new period. With the rise and development of jade carving design in higher-level education, the traditional model of mentoring inheritance is obviously not applicable to the modern higher education system. Through the combing of the jade carving inheritance method, the advantages and disadvantages of each inheritance method can be effectively summarized. We should draw lessons from the advantages of the traditional inheritance mode, combined with the current higher education mode and resources. On the basis of the existing teaching mode, jade carving teaching methods more suitable for the modern higher education system are explored. It is helpful to cultivate high-quality jade carving talents with high design level and practical technical level. The inheritance mode of higher education and the accumulation of talent training will become an important carrier and channel for jade carving art inheritance in the future.
\end{abstract}

\section{Keywords}

Traditional Mentoring Inheritance, Higher Education of Jade Carving Model, Approach, Characteristics

\section{Introduction}

China has a long history of jade making, whose people have been obsessed with the jade persistently. From fairy tales to historical biographies, records and praises about beautiful jade are overflowing in history. Exquisite jade tools were used in primitive social times thousands of years ago. From jade jue, jade axe and jade adzes unearthed in Xinglongwa culture more than 8000 years ago, to modern society, the production and use of jade in China have never stopped. Jade carv- 
ing technique is the technical means of jade culture. The jade carving technique has experienced long development and evolution. With the change of the times, the improvement of productivity level and jade carving tools are constantly updated. According to the division of jade-making tools, jade carving technology has experienced three stages: stone tools, bronze tools and iron tools. In the Neolithic Age, ancient ancestors used stones, animal bones and other tools to grind jade, leaving a large amount of exquisite jade for later generations under extremely simple and primitive conditions. During the Xia, Shang and Zhou Dynasties, bronze tools appeared. After the Warring States Period, the emergence of iron tools made jade-making tools more advanced and the production efficiency was greatly improved. In the Han Dynasty, jade workers invented jade special equipmentwater stool, which made China jade equipment occurred a qualitative leap (Kong, 2007). In modern times, electric jade carving machine and computer jade carving machine have become the main tools of jade making, jade making efficiency has reached the highest in history. In the process of inheritance in thousands of years, jade carving art has gradually formed a workshop-style mentoring teaching mode. And for a long period of time, it has become the main way of inheritance of the traditional jade carving skills. With the development of the times, the inheritance mode of jade carving skills has experienced the gradual evolution from mentoring inheritance, family inheritance to vocational education and higher education. Nowadays, the traditional mentoring teaching model is no longer applicable to the needs of the development of contemporary jade carving art. However, the modern higher education of jade carving and vocational education system is still not perfect, and it is still in the stage of continuous improvement. With the national revitalization and developed confidence in the traditional excellent culture, the exploration of cultivating high-quality jade carving talents at the higher education level is gradually carried out. The jade carving training mode in higher education has become an important part of the inheritance of the jade carving art today. It is important to analyze and summarize the characteristics of the traditional jade carving inheritance mode, combined with the characteristics of the current higher education jade carving training mode, and to provide theoretical support for the evolution and exploration of the jade carving art inheritance mode in the new era.

\section{Pros and Cons of the Traditional Jade Carving Master and Apprentice Teaching Model}

The mentoring and family inheritance of traditional jade carving workshops are the products of the times, and are determined by the ideology and the development level of productive forces. From the social environment at that time, the traditional jade carving skills, as an important means for practitioners and their families to maintain a livelihood, the inheritance was relatively conservative. In terms of inheritance mode, skill inheritance has a sense of site and intuition. The experience and steps of conception and creation are all influenced by learning, so as to complete the rich accumulation of the experience of smelting jade, which 
makes the traditional teaching mode is incompatible with the current educational concept that attaches importance to artistic personality. On the other hand, this model still has many advantages worth our reflection and learning from. From the favorable perspective, the teaching form of dictation and demonstration has the direct nature of obtaining theoretical and practical resources. From the favorable perspective, the teaching form of dictation and demonstration has the direct nature of obtaining theoretical and practical resources. First, the teaching form of oral and presentation has the immediacy of access to theoretical and practical resources. At the same time, the instilled on-site demonstration and guidance reduces the error of independent transformation of the subject and improves the efficiency of internalization. These forms have laid a solid foundation for the study of subject skill inheritance. Therefore, on the one hand, the traditional teaching ensures the inheritance of excellent experience; on the other hand, the clear inheritance of aesthetic standards reduces the probability of misunderstanding and learning. At the same time, the traditional mode of the exercise of the main practical ability is unattainable in the time and strength of teaching.

In terms of disadvantages, the traditional jade carving workshop-type apprenticeship model has its own limitations. The traditional jade carving workshop-type apprenticeship model also has its own limitations. The inheritance of master and apprentice is far more practical skills than aesthetic consciousness and more practical than artistic. In the copying of cramming teaching, the main aesthetic concept is not established, does not have the judgment of aesthetic consciousness, there is no screening type of absorption. In general, in the traditional mode of mentoring and apprentice teaching, the subjective concept of the subject is consciously weakened. The biggest difference between the current situations of higher education is that students already have a strong sense of independent aesthetic appreciation and creative concept before contacting with jade carving. Therefore, the created works are often closer to the public needs of aesthetic standards of the times.

\section{Characteristics of Jade Carving Teaching in Higher Education}

The educational environment and student quality sources of institutions of higher learning have been greatly improved compared with the traditional inheritance model. With the support of the existing educational resources, jade carving professional teaching presents an open and inclusive pattern. On the basis of inheritance, the contemporary aesthetic appreciation gradually integrates, and the works have a clear flavor of the times. Today's higher education jade carving teaching has the following characteristics:

\subsection{Weak Practice Foundation}

Jade carving is a practical plastic art. Exquisite craftsmanship is an important condition to highlight the connotation of jade culture. As the old saying goes, 
"The finest diamond must be cut", it also shows the concept of "unity between man and man" (Zhang, 2015). The thinking of the jade technology is the in-depth and perfection of the design creativity, which is the process of the image or schema transformation into the works (Zhao, 2017). Because of the hardness of jade material, the modeling is dependent on tools, forming the unique language and way of expression of jade carving. Mastering the characteristics of different types of tools, from conscious proficiency to unconscious skills, requires a large accumulation of practice. The application of Tuo wheel is a special process possessed by the jade carving process. With the differences in the application of the main body, it will create different visual and aesthetic characteristics, bring different aesthetic visual effects, and produce rich and changeable artistic language. The artistic quality of jade determines that its line and surface needs to be smooth and smooth, reflecting the elegant, smooth and soft beauty. The grasp of the overall beauty of jade is to find suitable tools on the basis of more practice. Dexterity and calm to master the use of different tools and expression techniques, to form a perfect jade carving process system. Nowadays, students lack or have less practice time, and the basic practice ability is weak.

\subsection{Coexistence of Inheritance of Excellent Traditional Folk Culture and the Expression of Free Thought}

The folk customs accumulated after a long historical process is the unique aesthetic psychology of our nation. In different historical periods, the decoration is often very different in the composition and the themes expressed ( $\mathrm{Gu} \mathrm{\&} \mathrm{Li,} \mathrm{2009).}$ In different historical periods, the decoration is often very different in the composition and the themes expressed. Pattern is the complete presentation of jade shape, to master the rich national pattern language and the law of pattern aesthetics. Learning the creation technique of symbol, homophonic and meaning is the necessary professional skills and quality of the accumulation of jade carving material language into the process of jade design and creative realization, which is also the basic condition to achieve the design intention with the jade as well as skills and realize the clever use of the layout. The volume of jade carving works and their aesthetic function determine the design of the pattern to achieve a concise effect. Therefore, the expression of the traditional jade carving pattern content is exaggerated and highly summarized according to the modeling characteristics of the jade article and the aesthetic needs of the main body. Jade carving design covers the author's unique creativity, is the embodiment of the comprehensive quality of smelting jade people. The unconventional jade carving design is the embodiment of the artistic style, connotation, form and the pursuit of innovative beauty in many aspects, which requires the flexible use of the auspicious pattern, form rules and exaggerated processing methods. In the teaching process of jade carving in higher education, on the basis of paying attention to the accumulation of traditional excellent culture and national pattern language, the main subject strengthens the consciousness of induction and generalization, and focuses on the cultivation of the ability of keen capture of material image characteristics. 
Guiding the main body emphasizes or expands the interesting part, so that its image is more distinct and prominent, and the formal charm and appeal of the image can be strengthened. At the same time, we encourage the combination of the material shape of jade, give full play to the basic image characteristics of the performance object, give full play to the artistic imagination, bold deformation, and recreate the image. The pursuit of the deformation of the pattern of fun and decency can avoid the overall layout after the flat sense. Therefore, the teaching process of modern jade carving does not limit students' thoughts and free the design direction. One is to associate according to the characteristics of jade; the second is to choose jade and jade according to the theme that the main body likes. Because the students have great autonomy in the direction of homework creation, the students have created a large number of novel and unique jade carving works. Many of these works break people's inherent impression of traditional Chinese jade carving works, retain the warm beauty of jade articles, convey the design concept of designers in the new era, and show the new ideas of the creation of jade carving works.

\subsection{Original Advantages}

Jade was not only spiritual wealth, but also material wealth in the ancient society. The beautiful luster and warm inner quality held by jade make it a supernatural object, endowed with humanistic beauty (Gu, 2003). Higher education jade carving teaching focuses on solid basic aesthetic education, and the precipitation of cultural cultivation deposits, which has laid a foundation for the creation and innovation of the beauty of jade culture. The advantage of strong learning and creative ability comes from the solid basic aesthetic education and good cultural cultivation. How jade carving carries out inheritance and innovation is not simply stuck on the demonstration of theoretical concept. It needs to be reflected through a lot of theoretical research and practice, and finally reflected by the complete practical creation. Nowadays, students have a relatively independent and mature aesthetic concept and master more theoretical knowledge of modern art and design. Higher education teaching adopts the teaching method combining theoretical guidance and technical guidance, which gives students more support in innovative works. In this teaching atmosphere, the students have created surprising works. In Figure 1 "Floating", the author shows the flexible form of jade carving. The jewelry was inspired by the jellyfish. When the jellyfish is in the movement, it uses the body to spray water to reflect forward, like an umbrella quickly drifts in the water. Jade usually gives people a classical and warm image. The author gives this jade jewelry a new feeling, and uses the combination of rose gold in the inlay. The inside of the jewelry is a small jade carving jellyfish, the outer outline uses rose gold inlaid with emerald, and the tentacles of the jewelry jellyfish can be held freely. There are two ways of wearing them as single earrings or pendants. In Figure 2, in "The Ear", the author takes Gobi jade as the raw material. Its light yellow color and special shape remind the author of his ears. The details of the work are exquisite, and the line turning point is decisive and vivid, 
showing the ears of the natural form.

\subsection{Strong Creative Ability of Today's Students}

The aesthetic education and literary literacy make students have a stronger overall control power and detail feeling power. Jade modeling is composed of the layout, arrangement and association of the design. Therefore, through a certain way of internal and form to make each part related to each other, to form a harmonious and orderly complete modeling style. On the presentation of jade carving works, it is necessary to achieve a rich, durable effect and a harmonious and implicit purpose. The most basic requirement is that the forms are both diverse and have the overall unity. It is innovative to seek unity in change, give change in unity, and strive to make the change of shape and unity to achieve perfect integration. From the micro point of view, the detail is the re-performance of the deep interpretation of the understanding of the subject. The details of the work also follow the principle of diversity and unity. Mr. Angle once pointed out that beautiful form is the layout of circular rate type. In the beautiful form,

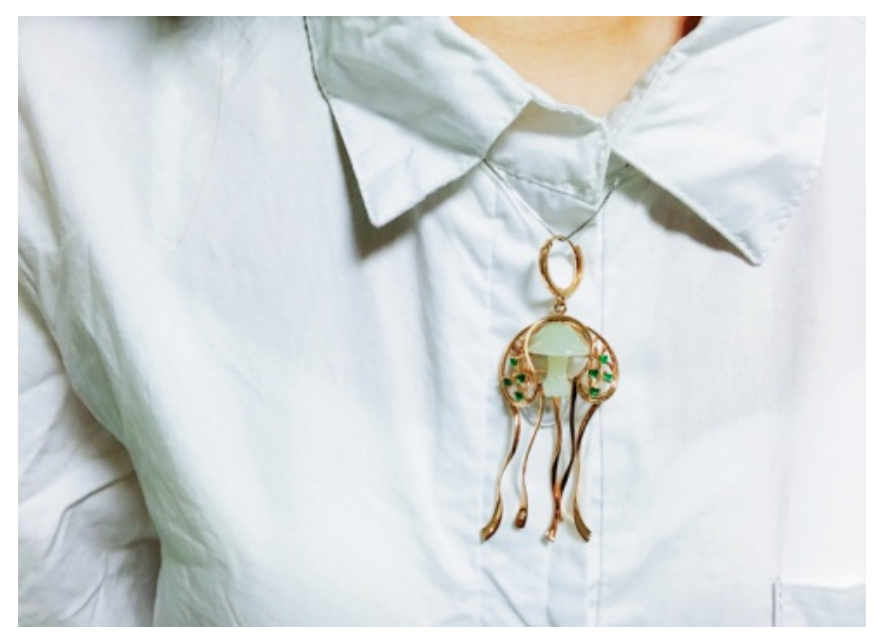

Figure 1. Floating (student: Zhoumin Ou).

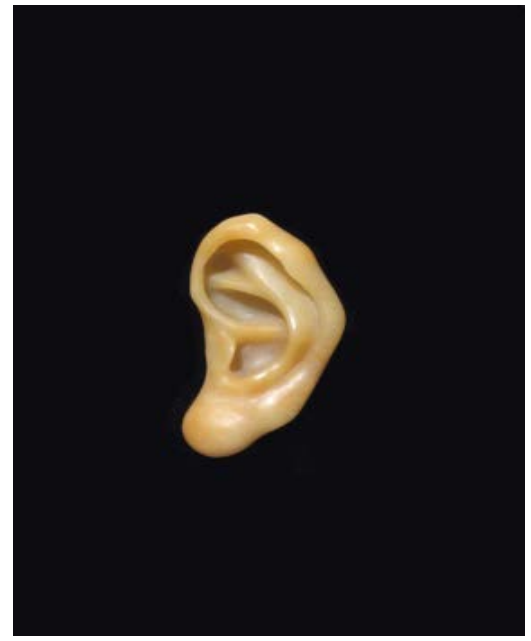

Figure 2. The Ear (student: Bitong Luan). 
everything is elastic and full, in which the details do not damage the general appearance. Traditional jade carving technology, detail control ability and control of the overall rhythm are important factors influencing the full display of details. Detailed performance is an important indicator to highlight the artistic quality and technological level. In Figure 3, The High Aspiration, based on the tone of grand scenes, focuses on depicting the characters and unifying the spirit of the characters with the theme. Content and form coordinate with each other, and scenarios blend with each other. The depiction of the background landscape details also makes the scene blend, and the content and form coordinate with each other. As a traditional handicraft inheritance art, artists in each historical period have a unique pursuit of detail performance and craftsmanship, leaving many amazing and popular works handed down to generation. Under the higher education system, it pays attention to the basic cultivation of students' humanistic quality, and focuses on the improvement of independent learning ability. The inheritors of traditional jade carving make it as a craft, and the practitioners rank themselves as craftsmen. Both the social environment and social status at that time determined that the industry could not generally accept cultural education. This has also become the biggest shackles affecting the industry positioning of the transformation from craft to arts and crafts. Therefore, the social environment of higher education makes students' overall aesthetic cultivation ability are better than that of traditional practitioners. Today's students often have stronger creative skills after improving their performance skills.

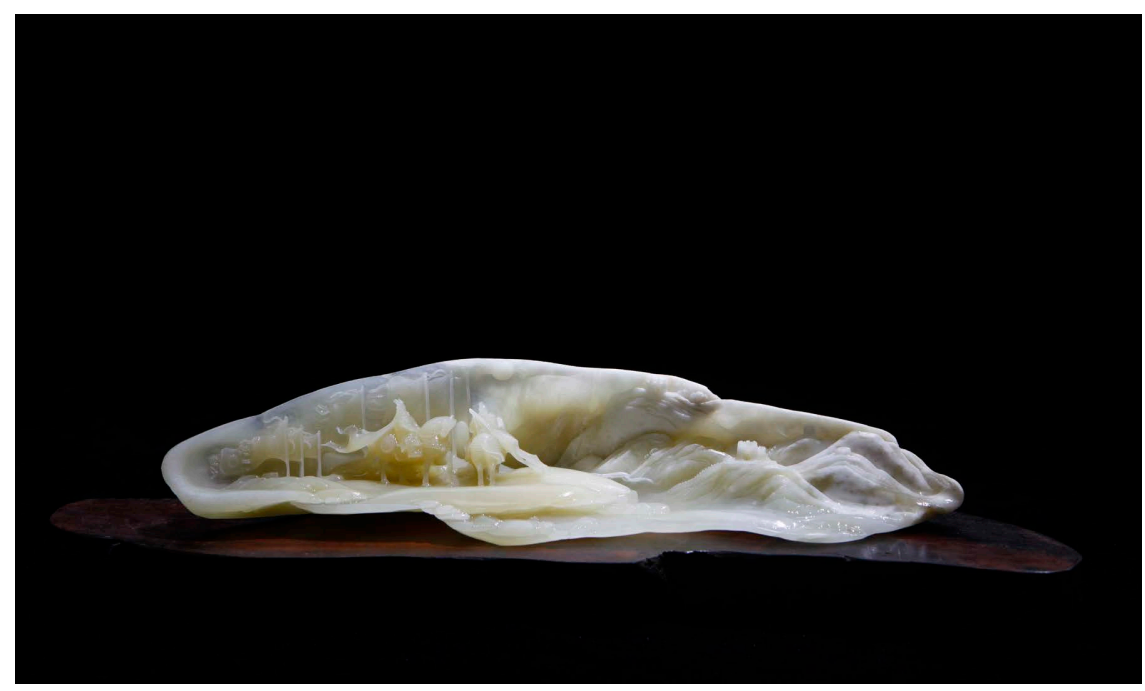

Figure 3. The High Aspiration (author: Chenglin Ming).

\section{Conclusion}

The master and apprentice inheritance system of traditional jade carving has paid more attention to the transmission of experience and skills. The students in this kind of system can quickly master the jade carving skills, and the operation ability can also be quickly improved through real and high-intensity practice. How- 
ever, the cultivation of the creators' subjective creation consciousness is lacking and the subjective aesthetic consciousness is weak. Reflected in the work is the same, lack of creativity can only pursue the peak in the "skill", and ignore the exploration of "art". So, the jade carving courses offered in the current institutions of colleges and universities focus on cultivating students' independent aesthetics and creativity. The restrictions of jade carving materials determine that the teaching mode of jade carving cannot be uniform. The selection of raw material with jade by the course design conception and the design according to the natural characteristics of jade material is beneficial to seek the best combination of creative ideas and jade material. Moreover, the open education mode of higher education expands the channels of cultural communication, which provides the convenience for the development of design thinking and the collision of design concepts. On the one hand, the inclusive education concept, while inheriting the exquisite craftsmanship and aesthetic value, it is conducive to the integration of modern art and design means, and enriches the craft and expression form of jade carving inheritance. Besides, the integration of multiple disciplines provides the possibility for the combination of comprehensive material creation and expands new channels for the inheritance and development of jade carving.

\section{Conflicts of Interest}

The authors declare no conflicts of interest regarding the publication of this paper.

\section{References}

Gu, F. (2003). Pure and Noble: Ancient Chinese Jade Culture. Sichuan People's Press House. Vol. 10, 10.

Gu, F., \& Li, H. J. (2009). The False Discrimination and Identification of Ancient Jade. Cultural Relics Publishing House, Vol. 2, 20.

Kong, F. A. (2007). Research on Jade-Making Technology in Ancient China. Ph.D. Thesis, University of Shanxi.

Zhang, J. T. (2015). The Interpretation of the "Materiality" and "Intangible Nature" of Contemporary Yangzhou Jade Carving. Master Thesis, Yangzhou University.

Zhao, P. C. (2017). Cutting and Carving-Jade. Shanghai Science and Technology and Education Publishing House, Vol. 1, 81. 